\title{
Immuno-chromatographic Analysis for HPV-16 and 18 E7 Proteins as a Biomarker of Cervical Cancer Caused by Human Papillomavirus
}

\author{
Joo-Ho Kim,,,+ Il-Hoon Cho, ${ }^{\ddagger, a}$ Sung-Min Seo, Ji-Sook Kim, ${ }^{\$}$ Kyu-Ha Oh, ${ }^{\$}$ \\ Heun-Soo Kang, In-Gyu Kim, ${ }^{\mathrm{P}}$ and Se-Hwan Paek ${ }^{+,+\cdots} \eta_{*}^{*}$ \\ -Gradtate School of Life Sciences and Biotechnology, and ${ }^{\ddagger}$ Program for Biolficrospstem Technologl, Korea Lniversitv, \\ Seoul 136-701, Korea. "E-mail: shpaek akorea.ac.hr \\ R\&D Center of Bio Focus Co., Ltd, 9F., Daehym Technow'orld, Gveonggi-do +37-753, Korea \\ "Metabolab Inc, Cancer Research Center, Seoul Kational Lniversitv, Seoul 110-799, Korea \\ ${ }^{\mathrm{P}}$ Department of Biochemistry and Molecular Biologv, College of Medicine, Seoul Kational University, Seoul 110-799. Korea \\ "Department of Biotechnologv and Bioinformatics, Korea Chiversitw, Jochin'on, Choongnam 339-800, Korea \\ Received October 16, 2009. Accepted November 3. 2009
}

\begin{abstract}
Among the more than 120 different types of human papillomavirus (HPV), types 16 and 18 have been known to be high risk agents that cause cervical cancer. We examined, in an immuno-chromatographic analysis, the potential of using the early gene product, E7 protein, as a diagnostic marker of cervical cancer caused by HPV. We developed monoclonal antibodies specific to HPV-16 and 18 E7 proteins that were produced from bacterial cells using gene recombinant technology. For each E7 protein, the optinal antibody pair was selected using the immuno-chromatographic sandwichty'pe binding system based on the lateral flow through membrane pores. Under these conditions, this rapid testing assay had a detection capability as low as $2 \mathrm{ng} / \mathrm{mL}$ of $\mathrm{E} 7$ proten. Furthermore, since viral analy sis required the host cell to be ly sed using chemicals such as detergents, it was possible that the E7 protein was structurally damaged during this process, which would result in a decrease in detection sensitivity. Therefore, we examined the detrimental effects caused by different detergents on the E7 protein using HeLa cells as the host. In these experiments, we found that the damage caused by the detergent, nonylphenylpolyethylene glycol (NP-40), was minimal relative to Triton X-100 commonly used for the cell lysis. Temperature also affected the stability of the E7 protein, and we found that the E7 protein was stabilized at $4{ }^{\circ} \mathrm{C}$ for about $2 \mathrm{~h}$, which was 4 times longer than at room temperature. Finally, a $\mathrm{HPV}$-infected cervical cancer cell line, which was used as a real sample nodel, was treated using the optimized conditions and the presence of E7 proteins were analyzed by immuno-chromatography. The results of this experiment demonstrated that this rapid test could specifically detect HPV-infected samples.
\end{abstract}

Key Words: Rapid test. Papillomaviruses. E7 protein as biomarker. Specimen stability. Cervix cancer

\section{Introduction}

Human papillomavinıs (HPV). a double-stranded small DNA virus. infects basal epithelial cells of the skin and the mucosal membrane of anogenital epithelium. HPV is thought to cause the most common sexually-transmitted viral disease ${ }^{1}$ and can lead to cancers of the cervix. vulvar. vagina. and anus in women. Numerous studies have reported that cervical cancer is mainly' caused by anogenital infection with high-risk HPV types. in particular. 16 and 18. " In their viral genomes two early genes. E6 and $E 7$, are known to act as viral oncogenes that promote tumor growth and malignant transformation in the host cells. ${ }^{3}$

The gene products. $\mathrm{E} 6$ and $\mathrm{E} 7$ proteins. deregulate the host cell growth cycle by binding and inactivating the tumor suppression protein p53. and retinoblastoma protein (pRb) of the host cell. respectively. ${ }^{+}$The E6 protein binds and degrades p 53 wia ubiquitin-dependent proteolysis. which leads to a loss of the cellular protein responsible for maintaining genomic stability." Since the E7 protein interferes with cell-cycle checkpoint regulators, it has been recognized as the most important oncogenic protein. ${ }^{6}$ For instance. in HPV-infected cervical cells. the E7 protein binds to the hypophosphorylated form of $\mathrm{pRb}$ and func-

\footnotetext{
${ }^{3}$ These authors equally contributed to this research.
}

tionally inactivates it. resulting in the liberation of the cellular transcription factor E2F-1. It has been reported that the E7 protein will be a valuable diagnostic marker for the detection of high-risk HPV types causing the cancer. ${ }^{8}$ Therefore, identification of the E7-related genotype or protein from HPV-16 and 18 is needed for the development of in vitro diagnostic assays.

For the past several decades papanicolaou-stained (Pap) smears have been used as the conventional method to detect abnomal or cancerous cervical cells in cervical smear specimens for the identification of cervical cancer. However the Pap smear test often produces a false negative or false positive result and it has been estimated that these false negative and false positive results have been responsible for 10 to $50 \%$ of the incorrect diagnoses. To intprove the test performance, liquid-based preparation and pre-screening smears ${ }^{1(1)}$ have been developed. However, these methods require technologically advanced pieces of equipment and expensive reagents. DNA-based methods ${ }^{11}$ may circunvent the intrinsic problems associated with achieving accurate diagnoses. However, the use of this technology is still limited because this method requires multiple reaction steps, long reaction times. well-equipped facilities, and welltrained personnel. In addition, the DNA-based detection methods are not adequate for monitoring the progress state of cancer. 
The aim of this study was to develop a potential alternative HPV detection method the immuno-chromatographic assay. which may not only be highly accurate but also rapid easy-touse. and inexpensive. The assay involves a one-step procedure where the complex antigen-antibody reactions are sequentially carried out by the lateral flow along the membrane strip upon the addition of a specimen. ${ }^{12}$ This concept was first demonstrated for the detection of fertility homones such as the human chorionic gonadotropin ${ }^{13}$ and luteinzing homone. More recenty this method was expanded to the analyses of various in witro diagnostic markers for infectious diseases. cancers, cardiac diseases and bio-terrorism agents. This methodology can be formulated as a qualitative kit using colloidal gold as a tracer, which is perceivable by the naked eye and also as a quantitative sensor by merely employing a colorimetric detector. ${ }^{14}$ Furthermore. in contrast to the DNA-based detection methods, the chromatographic assay can detect proteins as the analyte. which consequently allows one to monitor the progress state of illness.

In this study. we developed a chromatographic assay sy stem for the rapid detection of E7 proteins produced from HPVinfected cells. which was used as a model of a cervical cancer specimen. To construct the analytical sy'stem. monoclonal antibodies were raised against $\mathrm{E} 7$ proteins prepared using recombinant DNA technology. The capture and detection binders were then selected to form sandwich-type complexes for each analyte from the host cells. Caski and HeLa cell lines. which were infected with the model specimens. HPV-16 and 18 , respectively. Furthermore, the conditions used to prepare the specimen. such as the ly sing agent and treatment temperature. were optimized to minimize damage to the protein and maximize protein stability.

\section{Methods}

Preparation of HPV E7 proteins as immunogens. Protein expression: To produce recombinant HPV-16 and $18 \mathrm{E} 7$ proteins. complementary DNAs (cDNAs) corresponding to the respective E7 oncogene were separately cloned into the pGEX-4T-1 vector (GE Healthcare. Waukesha. WI), which contained a thrombin cleavage site (Leu-Val-Pro-Arg-Gly-Ser). ${ }^{15}$ The gene products were expressed as recombinant glutathione S-transferase (GST)E7 proteins in Escherichia coli ( $E$. coli) BL21(DE3). and the cells were harvested after cultivation. They were resuspended in $20 \mathrm{mM}$ Tris- $\mathrm{HCl}$. pH 7.5. containing $150 \mathrm{mM} \mathrm{NaCl} .0 .5 \%$ nonylphenylpolyethy lene glycol (NP-40) (Sigma. St. Louis. MO). $0.5 \mathrm{mM}$ dithiotheritol (DTT) (Sigma. St. Louis. MO), 2 $\mu \mathrm{g} / \mathrm{mL}$ phenylmethylsulphonyl fluoride (PMSF) (Pierce. Rockford. IL) and protease inhibitor cocktail (Sigma. St. Louis. $\mathrm{MO}){ }^{16}$ The cell lysate was allowed to incubate on ice for $30 \mathrm{~min}$. and centrifuged at $12,000 \mathrm{~g}$ at $4^{\circ} \mathrm{C}$ for $10 \mathrm{~min}$. The supernatant was then purified by affinity chromatography on a glutathione (GSH)-immobilized Sepharose 4B column ( $10 \mathrm{~mL}$ gel packing) (GE Healthcare. Waukesha. WI). The purified fusion proteins were cleaved by thrombin (GE Healthcare. Waukesha, WI) and the resulting $E 7$ proteins were finally quantified using the bicinchoninic acid (BCA) method (Pierce, Rockford, IL).

Charaterization: The GST-E7 proteins before and after thrombin cleavage were analyzed by sodium dodecyll sulfate
(SDS) polyacrylamide gel electrophoresis (SDS-PAGE) and Western blotting. The crude extract $(80 \mu \mathrm{g})$ was boiled in 120 mM Tris- $\mathrm{HCl}$ pH 7.9. containing $4 \%$ SDS. $0.02 \%$ bromophenol blue. $20 \%$ glycerol, and $2 \% 2-$ mercaptoethanol for $10 \mathrm{~min}$ and then loaded on a $15 \%$ gel for SDS-PAGE analysis. The PAGE gel was transferred to a nitrocellulose (NC) membrane $(0.45 \mu \mathrm{m}$ pore size) (Whatman. Kent. UK) for Western blotting. and the residual surfaces were blocked in $10 \mathrm{mM}$ phosphate buffer, $\mathrm{pH}$ 7.4, containing $140 \mathrm{mM} \mathrm{NaCl}$ (PBS) and $0.5 \%$ casein (CaseinPBS). The membrane was prepared in duplicate and then incubated in polyclonal anti-HPV-16 E7 and anti-HPV-18 E7 antibodies ( Santa Cruz, CA), respectively. diluted in Casein-PBS containing $0.1 \%$ tween-20 (Casein-PBS-TW) for $1 \mathrm{~h}$. The membranes were treated with anti-goat IgG antibody coupled to horseradish peroxidase (HRP: Invitrogen, Carlsbad. CA) in the same medium and signals were finally produced by incubating them with the Western blotting substrate (Pierce, Rockford. IL).

Production of monoclonal antibodies. Antibody production: Monoclonal antibodies specific for the HPV-16E7 and HPV-18 E7 proteins were prepared as described elsewhere. ${ }^{16}$ Briefly, $\mathrm{Balb} / \mathrm{c}$ fenale nice ( 8 weeks old) were immunized by intraperitoneally injecting $10 \mu \mathrm{g}$ of the recombinant HPV-16 and $18 \mathrm{E} 7$ protein after nuxing with an equal volume of Complete Freund's adjuvant (Sigma. St. Louis. MO). After 2 weeks, the nice were immunized with the same antount of the $E 7$ proteins emulsified with Incomplete Freund's adjuvant (Sigma. St. Louis. $\mathrm{MO}$ ). The same procedure was repeated 2 weeks later, and the final boosting was conducted after the same period with $\mathrm{E} 7$ proteins dissolved in PBS. Three days after the injection of the final boost. the mouse splenocytes were collected and fused with murine myeloma cell (sp2/0-Agl4) (American Type Culture Collection: ATCC, Manassas, VA), which was used as a fusion partner. Fused hybridona cells were screened based on hypo:anthine aminopterin thymidine (HAT: Gibco BRL, Gaithersburg. MD) selection, and hybridona clones exhibiting high titers of binding activities to each $\mathrm{E} 7$ protein were selected by immunoassays using antigen-coated microtiter plates. The selected hybridoma cells were injected into 2,6.10.14-tetramethylpentadecane pristane (Sigma. St. Louis. MO)-primed female $\mathrm{Balb} / \mathrm{c}$ mice to produce the antibodies as ascitic fluid, which was then purified on a protein $\mathrm{G}$ column ( $5 \mathrm{~mL}$. HiTrap protein G HP) (Amershan Biosciences. Piscataway. NJ). Each antibody concentration was determined by absorbance measurement at $280 \mathrm{~cm}$.

Isotype (ketemination: The sub-isotypes of the produced antibodies were determined using an enzy me-linked immunosorbent imnumoassay (ELISA)-based mouse monoclonal isotyping kit (Pierce. Rockford. $\amalg$ ) according to the manufacturer 's instructions. Briefly. $25 \mu \mathrm{g}$ of the goat anti-nouse imnumoglobulin $(\mathrm{G}+\mathrm{A}+\mathrm{M})$ antibody was coated on the inner surfaces of the microwells at room temperature for $2 \mathrm{~h}$, the residual surfaces were blocked. $50 \mu \mathrm{L}$ of the monoclonal antibody samples were reacted at $37^{\circ} \mathrm{C}$ for $\mathrm{l} \mathrm{h}$. the subclass-specific rabbit anti-mouse imnunoglobulin antibodies were subsequently bound. and alkaline phosphatase-conjugated anti-rabbit immunoglobulin G (IgG) antibody was finally added. The colorimetric signals from each well were produced via the enzy me-substrate reaction.

Scleening of antibodies for rapid testing. Antibody labeling 
with colloidal gold: A monoclonal antibody selected as the detection binder was labeled with colloidal gold (the mean diameter: $30 \mathrm{~nm}$ ) as previously reported. ${ }^{17}$ Briefly, the antibodies dialyzed in $10 \mathrm{mM}$ phosphate buffer were conjugated with colloidal gold that was syththesized using the sodium citrate method. Unreacted antibodies were removed by centrifugation and the antibody-gold conjugates were then resuspended in CaseinPBS such that the gold density was concentrated by 20 -fold relative to the initial gold density.

Immuno-strip preparation: The rapid test kit for $\mathrm{E} 7$ proteins was constructed by combining different functional membrane strips as described elsewhere. "The four membrane pads used in assembling the rapid test kit were as follows (from the bottom): a glass fiber membrane $(+\times 20 \mathrm{~mm})$ (Allstrom. Whatman Kent. UK) for sample application, a glass fiber membrane $(4 \times 7 \mathrm{~mm})$ (Alistrom. Whatman. Kent. UK) for the release of the detection antibody labeled with colloidal gold. a NC membrane $(4 \times 25$ $\mathrm{mm}$ ) (Millipore. Billerica, MA) for signal generation and a cellulose membrane $(4 \times 50 \mathrm{~mm}$ ) (Allstrom. Whatman Kent. UK) for continuous sample absorption. The sample application pad was prepared by immersing in $10 \mathrm{mM}$ Tris- $\mathrm{HCl}$, pH 7.5. containing $0.1 \%$ Triton $\mathrm{X}-100$ and drying at $55^{\circ} \mathrm{C}$ for $+\mathrm{h}$. The signal generation pad was prepared by spotting a monoclonal antibody $(\mathrm{I} \mu \mathrm{L}$ ) selected as the capture binder on the $\mathrm{NC}$ membrane and then allowing it to incubate at $37^{\circ} \mathrm{C}$ for $20 \mathrm{~min}$. The four membrane pads were partially superimposed in length to constnıct the immuno-strip.

Antibody pair selection: To select antibody pairs for the analy ses of each $\mathrm{E} 7$ protein. the produced monoclonal antibodies were used as either the capture antibody or the detection antibody. E7 protein ( $1 \mu \mathrm{g} / \mathrm{mL}: 100 \mu \mathrm{L})$ in Casein-PBS was added to each microwell containing a detection antibody ( 20 -fold concentrate: $2 \mu \mathrm{L}$ ) labeled with colloidal gold and reacted for $5 \mathrm{~min}$. The immuno-strip with an immobilized capture antibody was then immersed into the reaction misture and. after 15 min. the color signal that appeared on the capture antibody site was stored as image in a personal computer. The signals corresponding to each combination of antibodies were finally used to select the best pairs.

Detemination of sample preparation conditions. Antibody labeling with HRP: Since the E7 protein may be denatured by the use of HPV-host lysing agents such as detergents. the structural stability of the protein was determined by ELISA employing HRP as the tracer. The detection antibodies. clone \#35 and \#1 specific to HPV-16 E7 and HPV-18 E7 proteins. respectively. were separately coupled to HRP wa a chemical reaction as previously described. "Briefly, the antibodies were first reduced using DTT ( $10 \mathrm{mM}$. final concentration) and the excess reagent was removed on a Sephadex G-15 gel filtration column (GE Healthcare. Waukesha. WI). HRP was activated with a 50 -fold molar excess of succinimidyl +-[N-maleimidomethỵl] cyclohexane-1-carboxylate (SMCC; Pierce. Rockford. IL). and the excess reagent was immediately removed in the same manner. Each antibody was then combined with a 5 -fold molar excess of the activated HRP and the conjugation was carried out at 4 ${ }^{\circ} \mathrm{C}$ overnight.

Cell lysis medium conditions: The HeLa cell line (ATCC. Manassas. VA) was used as a model HPV-infected specimen and grown in the culture media reconmended by the supplier. The cells were maintained in dulbecco"s modified eagle"s medium (DMEM: Therno scientific. Hýclone. Waltham. MA) supplemented with $10 \%$ heat-inactivated fetal bovine serum (FBS: Gibco BRL, Gaithersburg. MD) and at the time of analy'sis. the cells were harvested by treatment with trypsin (Gibco BRL, Gaithersburg. MD). After washing with PBS, the harvested cells were lysed for $\mathrm{E} 7$ protein extraction at room temperature using different media: Medium a: $50 \mathrm{mM}$ Tris-HCl. $\mathrm{pH}$ 7.5. containing $150 \mathrm{mM} \mathrm{NaCl} .0 .5 \%$ bovine senum albumin (BSA: Basic mediunt). $1 \%$ Triton X-100. and protease inlubitor cocktail (1: 20 dilution): Medium b: Basic medium supplemented with $0.5 \%$ NP-40: and Medium c: Basic medium supplemented with $0.5 \%$ NP-40 and the protease inhibitor cocktail. The time between lysing the sample and subjecting it to ELISA analy'sis for HPV$18 \mathrm{E} 7$ protein detection. as described below, was varied from $5 \mathrm{~min}$ to $8 \mathrm{~h}$.

Lysis temperature: HeLa cell lysis with Mediun c was carried out separately at $4{ }^{\circ} \mathrm{C}$ and room temperature. The lysed cells were left at each condition for different time intervals $(5$ min to 16 h) prior to ELISA analysis for HPV-18 E7 protein detection.

ELISA: The immunossay used for HPV-18 E7 protein detection was carried out using the detection antibody (clone \#1) labeled with HRP and the capture antibody (clone \#36) immobilized on the surfaces of nicrowell. The capture antibody (1 $\mu \mathrm{g} / \mathrm{mL}: 100 \mu \mathrm{L})$ in PBS was added into the wells and incubated in a container maintained at $100 \%$ humidity and $37^{\circ} \mathrm{C}$ for $\mathrm{l} \mathrm{h}$. After washing with deionized water. the residual surfaces were blocked with PBS containing 3\% BSA under the same conditions. The test samples ( $100 \mu \mathrm{L}$ ) containing the $\mathrm{E} 7$ protein and the labeled detection antibody (1:1.500 dilution: $25 \mu \mathrm{L})$ in Casein-PBS were sequentially reacted in the microwells. The incubation conditions were identical to those used above and a thorough washing was conducted after each reaction. The enzyme substrate containing $100 \mu \mathrm{L}$ 3.3'.5.5'-tetramethylbenzidine (TMB: Sigma. St. Louis. MO) was added into each well and reacted for $15 \mathrm{~min}$ at room temperature. $1 \mathrm{M}$ Sulfuric acid $(50 \mu \mathrm{L}$ ) (Sigma. St. Louis. MO) was finally added to stop the enzyme reaction, and the colors produced in each well were determined by measuring the absorbance at $450 \mathrm{~nm}$.

Analytical perfomances of the rapid test kit. Rapid test kit: Immuno-strips were constructed using the antibody pairs most suitable for detection of the respective $\mathrm{E} 7$ proteins to examine the detection limits for each analyte. Two monoclonal antibodies. clone \#35 and clone \#1, specific to HPV-16 and 18 E7 proteins. respectively, were labeled with colloidal gold as described above. The conjugate pad was prepared by spraying the two detection antibodies on the glass fiber membrane and drying it at $35^{\circ} \mathrm{C}$ overnight. The signal generation pad was prepared by immobilizing the following three different antibodies on spatially separate sites of the NC membrane (from the bottom): the capture antibody to HPV-16 E7 (clone \#119). the capture antibody to HPV-18 E7 antibody (\#36). and an anti-mouse IgG polyclonal antibody as the control. They were dispensed on each pre-determined site in a linear pattem on the NC membrane and then incubated at $37^{\circ} \mathrm{C}$ for 20 min. The sample application pad and absorption pad were prepared as described earlier. and the four membrane pads were assembled to fabricate the im- 
muno-strip. which was then placed within the pre-designed plastic cassette.

Detection capability: To determine the detection limit of the rapid test kit. the standard samples were first prepared with the HPV-16 E7 protein and HPV-18 E7 protein, respectively. The stock protein solution was serially diluted with Casein-PBS to various concentrations ( 1 to $10 \mathrm{ng} / \mathrm{mL}$ ). Each sample solution $(400 \mu \mathrm{L})$ was transferred into the sample application pot of the cassette and the antigen-antibody reactions were carried out for $15 \mathrm{~min}$. The color signals produced from the respective assay were stored as images in a personal computer.

Cevical cancer cell line test: Four cell lines (ATCC. Manassas, VA). Caski, HeLa. MCF7, and A549. were used as models of HPV-infected cell specimens. Caski cell. which is a cervical cancer cell. was infected with HPV-16 and employed as the positive specimen for the HPV-16 E7 protein. HeLa cell, another cervical cancer cell, was infected with HPV-18 and used as the positive specimen for the HPV-18 E7 protein. MCF-7 and A549. breast cancer and lung cancer cell lines. respectively. were used as the negative controls. The four cell lines were separately cultured in DMEM media containing $4 \mathrm{mML}$-Glutamine, $4.5 \mathrm{~g} / \mathrm{L}$ glucose. and sodium py ruvate. supplemented with hypoxanthine thymidine (HT) supplement (Gibco BRL. Gaithersburg. $\mathrm{MD}$ ), antibiotic-antimýcotic (Gibco BRL. Gaithersburg. $\mathrm{MD}$ ). and $10 \% \mathrm{FBS}$. After maintaining the cultivations in healthy states. each cell was harvested by treating the adherent cells with trypsin. The cells (approximately $\mathrm{I} \times 10^{6}$ cells each cell line) were washed twice with PBS and then lysed in Medium c ( $400 \mu \mathrm{L}:$ see above). Each cell lysate was centrifuged at $400 \mathrm{~g}$ for $10 \mathrm{~min}$ and the supematants were collected as the analytical samples for use in the rapid testing kit. All test procedures ( 400 $\mu \mathrm{L}$ sample each test) were the same as described above.

\section{Results and Discussion}

Recombinant HPV E7 proteins. Recombinamt protein production: Since E7 proteins from HPV-16 and 18 are not currently commercially available. we needed to manufacture them to use as standard materials for screening optimal antibody pairs and evaluating the sandwich immunoassay systems. By employing recombinant technology. ${ }^{18} \mathrm{HPV}-16$ and $18 \mathrm{E} 7$ fusion proteins with GST were produced from microbial cells through cultivation. The SDS-PAGE analysis revealed that the constituents in the culture broth concentrates were heterogeneous (Figure 1, A) and. thus. the E7 hision proteins with GST were purified on a GSH coupled-Sepharose gel chromatography column. ${ }^{19}$ When the purified fraction was subjected to SDS-PAGE analysis. a major band near $49 \mathrm{kDa}$ was observed for the both HPV strains (Figure 1. B). Although other minor components were also observed the purity of the target proteins were greater than $98 \%$ based on a comparison of the band areas. Since the molecular weight of GST was about $37 \mathrm{kDa}$, the $\mathrm{E} 7$ alone was approximately $12 \mathrm{kDa}$ in size

Molecular characterization: The produced fusion proteins were cleaved using thrombin to obtain the $E 7$ proteins for each HPV strain and then characterized via Westem blotting (Figure 2). Each component was probed with the commercially available specific polyclonal antibodies. In this analysis the fusion pro-

\section{SDS-PAGE for GST-E7 fusion protein}

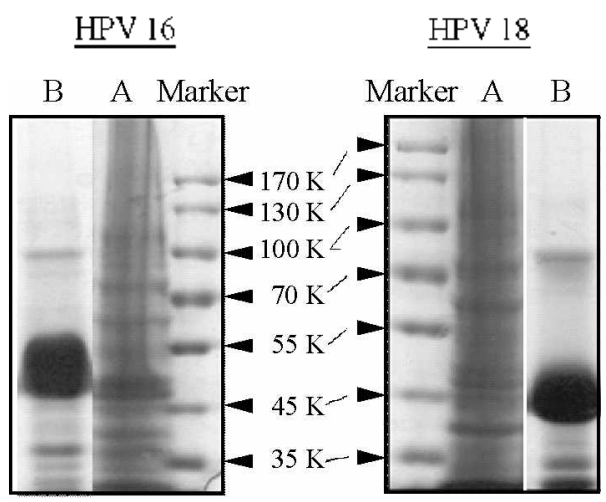

Figure 1. SDS-PAGE analyses of recombinant GST-HPV-16 and 18 E7 fusion proteins expressed in E. coli BL21 (A) and then purified by GSH-Sepharose gel chromatography (B). The GST-E7 protein band was detected at a molecular weight of approximately $49 \mathrm{kDa}$ after fractionation.

\section{Westem blot for $\mathbf{E 7}$ protein}

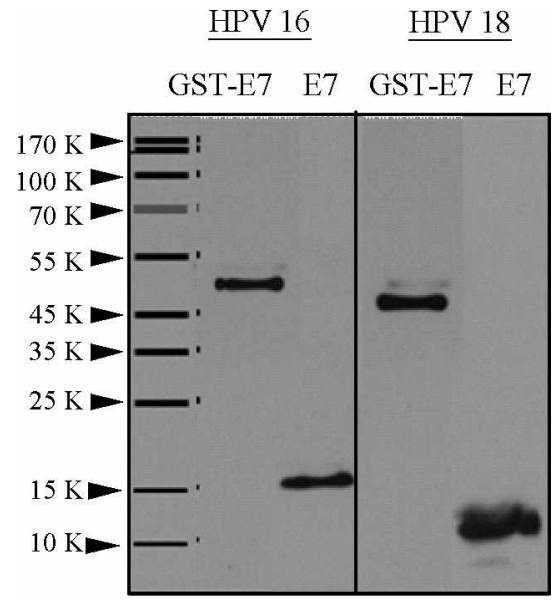

Figure 2. Western blotting analyses of HPV- 16 and 18 E7 proteins before and after thrombun cleavage. Pror to cleavage, the fulsion proteins (GST-E7) were monitored using a polyclonal antibody to GST. The cleaved products (E7) were also probed using polyclonal antibodies specific to each E7 protein. Based on this analysis, the molecular weights of HPV-16 E7 and HPV-18 E7 were approximately $16 \mathrm{kD}$ a and $12 \mathrm{kDa}$, respectively

teins (GST-E7) were found to be approximately the same in the molecular size as mentioned above. However after cleavage. there were slight differences in the size of the $\mathrm{E} 7$ protein $(\mathrm{E} 7)$ from each strain. Even though all E7 genes were recombined with the same GST gene. they may be expressed at different sizes depending on the included gene size of the vector when translated. According to a previous report. ${ }^{18}$ the bacterially expressed His-tagged HPV-16 E7 protein appeared as a predominant band at $16 \mathrm{kDa}$ even though the theoretical molecular weight of the $\mathrm{E} 7 \mathrm{His}_{i}$ monomer was $12.1 \mathrm{kDa}$. Under the con- 


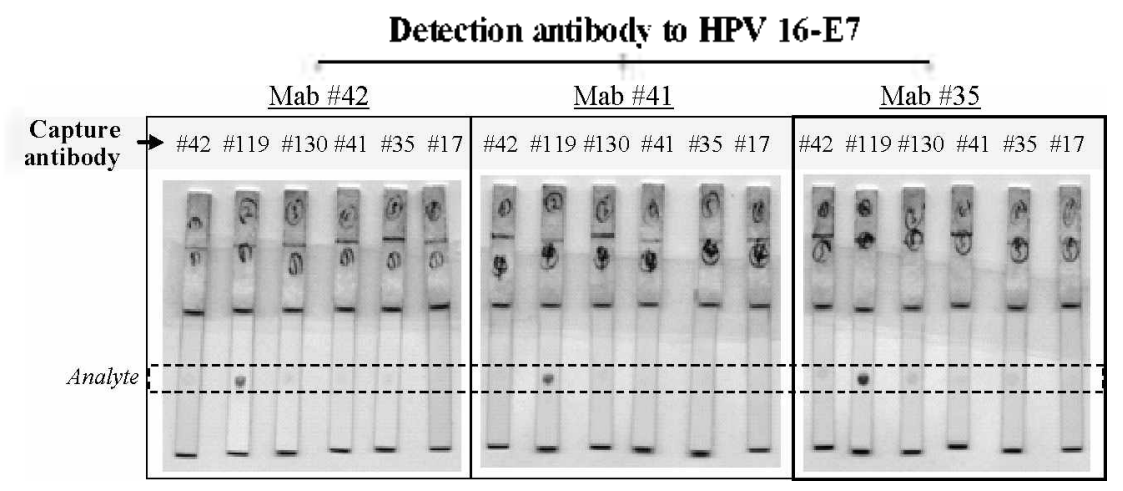

Figure 3. Selection of an optimal antibody pair that could simultaneously bind to the HPV-16 E7 protein molecule via immuno-chromatographic assay. One of the produced antibodies was inmobilized as the capture binder on the NC membrane surfaces and the other was labeled with colloidal gold and used as the detection antibody. The assays were carried out by systematically combining the capture and detection antibodies and the signals resulting from the sandwich complex fomation were compared.

ditions used in this stidy the free HPV-16 and 18 E7 proteins were found to be about 16 and $12 \mathrm{kDa}$ in size, respectively, and had the appropriate molecular structure since they were able to bind to the corresponding specific antibody

Optimal immuno-analytical conditions. In cervical cancer diagnosis. monoclonal antibodies have been used to immunologically stain cancer cells..$^{37}$ which may overcome some of the drawbacks associated with the conventional histochemical method the Pap smear. Although immuno-staining has the potential to specifically detect cancer with a single antibody, it often produces a false positive result due to the non-specific binding of the labeled-secondary antibody employed for signil generation. To alleviate such problems, we developed a sandwich-type binding system. the immuno-chromatographic assay, which is based on the lateral flow of the membrane and has an additional advantage in regards to point-of-care testing. ${ }^{1 ?}$

Optimal antibody paining: Among the monoclonal antibody pools previously established for HPV- 16 and 18 detection ${ }^{16}$ we selected antibody pairs that could simultaneously bind to the respective $E 7$ protein molecule. To screen by means of immunochromatography. an antibody' to the HPV-16 E7 protein was used as the capture binder by immobilizing it on a pre-determined site of the NC membrane and the other antibodies were used for detection by labeling them with colloidal gold. After carrying out the chromatographic assay's. the color signals that appeared on the capture antibody sites were then compared with each other to select the antibody pair (\#119 as the capture and \#35 as the detection) that yielded the highest complex formation with the analyte (Figure 3). The same procedure was used to select the most optimal antibody' pair for the HPV-18 E7 protein assay (antibody \#36 as the capture and $\# 1$ as the detection) (results not shown). Furthermore. the selected monoclonal antibodies were subtyped using a commercially available kit and antibodies \#119 and \#1 were determined to be the $\operatorname{IgG}_{\approx} \mathrm{b}$ type, and $\# 35$ and $\# 36$ were the $\operatorname{Ig} G_{\text {2a. }}$.

Detection capability for $\mathbf{E} 7$ protein: The antibody pairs for the respective analyte were used to constnict the rapid test kit and the experimental conditions were optimized to maximize the detection capability of the kit. The major factors, including the concentration of the capture and detection antibodies. and
Table 1. Determination of detection capabilities of the immuno-chromatographic assays for HPV- 16 and $18 \mathrm{E} 7$ proteins under optimal conditions

\begin{tabular}{cccccccc}
\hline & \multicolumn{6}{c}{ E7 protein concentration in standard sample } \\
\cline { 2 - 7 } Test results & 10 & 8 & 6 & 4 & 2 & 1 \\
& $\mathrm{ng} / \mathrm{mL}$ & $\mathrm{ng} / \mathrm{mL}$ & $\mathrm{ng} / \mathrm{mL}$ & $\mathrm{ng} / \mathrm{mL}$ & $\mathrm{ng} / \mathrm{mL}$ & $\mathrm{ng} / \mathrm{mL}$ \\
\hline For HPV-16 E7 & ++ & ++ & ++ & ++ & + & - \\
For HPV-18 E7 & ++ & ++ & ++ & ++ & + & - \\
\hline
\end{tabular}

-- : Strong signal: +: weak signal; and $-:$ no signal produced.

the lateral flow rate along the immuno-strip, were optinized as described in our previous reports. "Standard samples of the target proteins were prepared and used to analyze the inununochromatographic assay according to the pre-determined protocol. The results of this experiment revealed that the produced signals were proportional to the analyte concentration and detectable by the naked eyes at an analy te concentration as low as 2 $\mathrm{ng} / \mathrm{mL}$ for the both of HPV-16 and 18 E7 proteins (Table 1).

Although there have been no clear reports regarding the levels of $\mathrm{E} 7$ protein in cervical cancer cells infected by HPV, they could be present in trace anounts in real samples. ${ }^{21}$ This suggests that the detection capability of the immuno-chromatographic assay may not be sufficient for clinical applications. and a more sensitive analytical method such as ELISA-based rapid testing $=$ may need to be employed in the future. Furthermore, variations in the level of the $\mathrm{E} 7$ protein as a function of the progress of the virally infected disease should also be clinically determined.

Cenvical cancercell line tests. The $\mathrm{E} 7$ protein produced from cells infected by HPV-16 or 18 has been reported to be unstable during storage. ${ }^{23}$ This instability could be even worse after the cells have been treated with a lysing agent. such as detergents. during protein extraction. Thus, the lysis conditions, such as the detergent type and temperature. were tested in order to deternine the effect of these factors on protein stabilization. The residual activities of the extracted proteins were deternined by microtiter plate-based immunoassays (e.g., ELISA) using the same capture and detection antibody pairs as selected above for each E7 protein. 
A) Effect of lysis medium

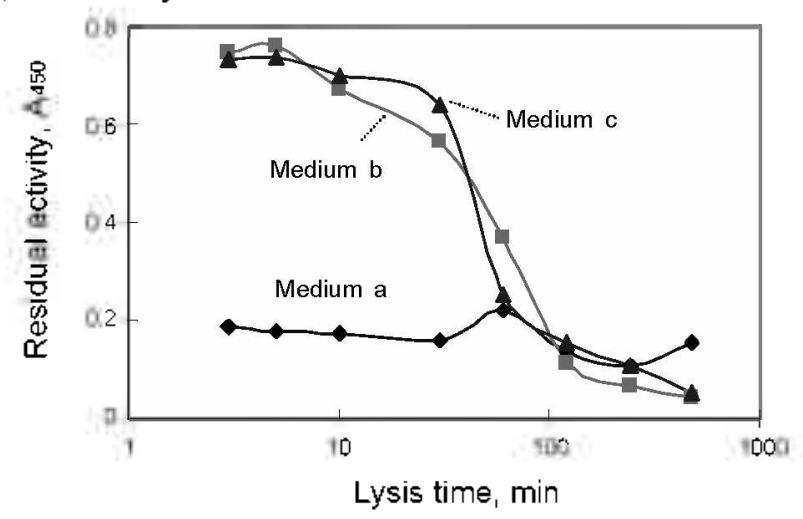

B) Effect of lysis temperature

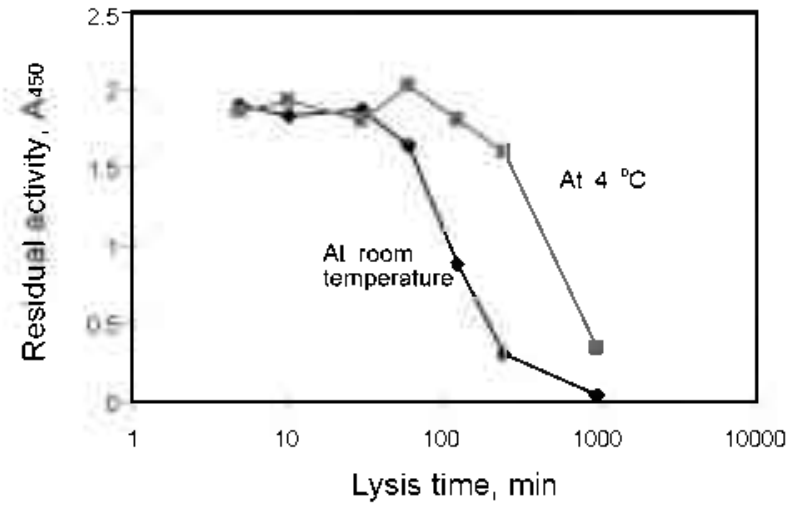

Figure 4. Eftect of lysis medium (A) and temperature (B) on the integrity of the E7 protein produced from HeLa cells by HPV- 18 infection. Three different lysis media were employed in test A: 'Medium a' contained Triton X-100 as the lvsing agent, and 'Media b and c contained NP-40 as the lysing agent. Furthemore, 'Media a and c' included a protease inhibitor, but 'Medium b' did not. In test $\mathrm{B}$, the $\mathrm{E} 7$ protein integrity was examined at two different temperatures, $4^{\circ} \mathrm{C}$ and room temperature.

Lysis medium composition: For testing in a real sample preparation, we selected the cervical cancer cell line. HeLa cells. as a model host for HPV-18 infection. Among the cell lines derived from the same source the HeLa cell line was the most appropriate for this study since the cells were cultivated fairly fast in nonmal medium (e.g., DMEM) and reproducibly produced the E7 protein. HeLa cells have also been used for studying the role of E7 protein in HPV-induced cancer. ${ }^{2+}$ The cultivated HeLa cells were lysed using three different types of media each containing a different composition of lysing agent and protease inhibitor. and the protein integrity under each condition were quantitatively monitored as a function of treatment time (Figure 4. A). For the protein integrity test, an ELISA sy stem was devised by chemically coupling the detection antibody to the enzyme. HRP, and by coating the capture antibody on the surfaces of the microwells. Under these conditions the system was able to detect a minimum of $1.0 \mathrm{ng} / \mathrm{mL}$ of $\mathrm{E} 7$ protein.

When the ly sis medium contained Triton X-100 as the cell breakage agent (Medium a). the protein activity was initially so low that only a small portion of the applied molecules seemed to be intact (Figure 4. A). The stnictural degradation rate. there-

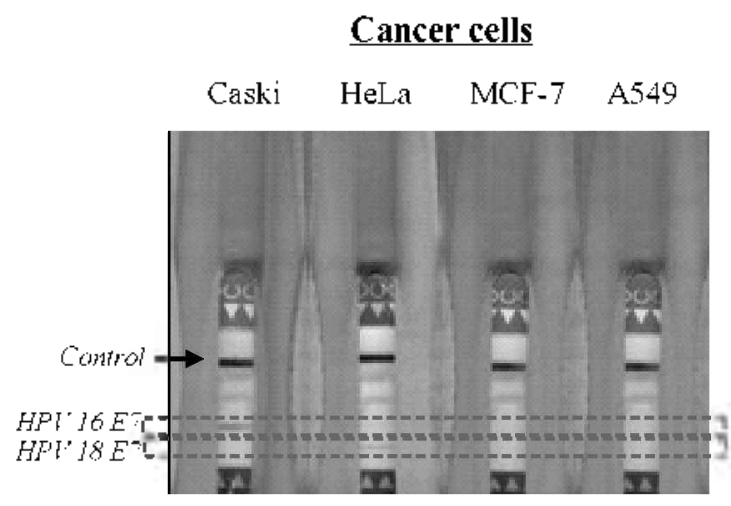

Figure 5. Rapid test results for HPV-E7 proteins produced from different cervical cancer cell lines. Positive indicators for the protein employed here were Caski cell with HPV-16 infection and HeLa cell with HPV- 18 infection. MCF-7 and A549 cells were used as negative controls. The cells under cultivation were lysed and used as samples for the rapid testing. The rapid test immuno-strip was prepared to simultaneously detect the two different E7 proteins on distinct analyte lines marked as HPV-16E7 and HPV-18 E7, respectively. The control line was also made on the top position of the analyte lines.

after, was quite slow as a function of incubation tine. When NP40 was used as the lysing agent (Media $b$ and $c$ ). the initial protein integrity was significantly improved and was 3.5 times higher than that when Triton X-100 was used, but abruptly decreased 10 min after onset of treatment. Such enhancement effect of NP-40 has also been previously reported..$^{25}$ In contrast. the effect of the protease inhibitor contained in 'Media a and $c$ ' was relatively insiguificant. Nevertheless. no matter what cell lysis media were used, treatment times longer 100 num seemed to completely degrade the protein integrity. These data indicate that the detergent. Triton X-100, which is conventionally used to ly'se cells. should be replaced with NP-40 for E7 protein extraction and the ly sis time should be short prior to analysis.

Temperature effect: Further tests were performed to determine the optimal temperature for $\mathrm{E} 7$ protein extraction from the HeLa cell culture. Cell lysis was carried out using the optimal medium (i.e. "Medium $c$ ' in Figure 4. A) at two different temperatures. $4^{\circ} \mathrm{C}$ and room tenperature. HPV- 18 E 7 protein activity was determined as a function of time using ELISA as described above (Figure 4, B). These experiments showed that the protein integrity in the cell lysate was maintained at $4{ }^{\circ} \mathrm{C}$ for $2 \mathrm{~h}$. while it was only maintained for $30 \mathrm{~min}$ when kept at room temperature. This result indicated that upon treatment, even with NP-40 as detergent, it is essential to maintain the cell lysate at low temperature prior to analysis.

Rapid test peifomance: To detect the presence of $E 7$ proteins via immuno-chromatography, we first prepared HPV-infected cell lines that closely mimicked clinical samples used for cervical cancer diagnosis. These model HPV-infected cells lines were HPV-16-infected cervical cancer cell line. Caski cell. and a HPV-18-infected cell line. HeLla cell. In addition two HPV-negative cells, MCF-7 and A549, were also used as controls. After culturing the cell lines under optimal conditions. analytical samples were prepared by lysis and then subjected to immunoassays for detection of $\mathrm{E} 7$ proteins using the rapid test kit (Figure 5). The immuno-strip was made to detect HPV-16 and $18 \mathrm{E} 7$ pro- 
teins at the same time by immobilizing each capture antibody (as indicated above) at spatially separate sites on the NC membrane. Identical detection antibodies labeled with colloidal gold were also employed. In addition the control line, which generated a color signal regardless of the analyte dose. was located on the top of the analy te lines by coating a secondary antibody that binds to the mouse IgG.

From the test results shown in Figure 5. the two HPV-infection positive cell samples, Caski cell and HeLa cell. were detected on each analyte line. HPV-16 E7 and HPV-18 E7, respectively. on the imumuno-strip. The infection-free samples, MCF-7 cell and A549 cell. did not exhibit any signals at the analyte lines. These results demonstrated that the rapid testing was not only highy specific. but also capable of detecting $\mathrm{E} 7$ proteins produced from cancer cells infected with HPV.

\section{Conclusions}

The $\mathrm{E} 7$ protein an oncogene product of HPV. was detected from host cells using an immunoassay, indicating that this protein can be used as a diagnostic marker for cenical cancer caused by HPV infection. To obtain immunogens. high-risk HPV types 16 and $18 \mathrm{E} 7$ proteins were produced via DNA recombination at molecular sizes of approximately 16 and $12 \mathrm{kDa}$. respectively. The monoclonal antibodies specifically raised against the recombinant proteins were suitable for constructing the rapid test kit based on immuno-chromatography, which could simultaneously measure both analytes. In consideration of clinical tests for cancer diagnosis. we also determined the optimal conditions for handling the host cell such that the extracted E7 protein could be stable at $4^{\circ} \mathrm{C}$ for $2 \mathrm{~h}$. Although this rapid testing kit showed a clear discrimination between the HPV infected and normal cells, the detection capability may not be sufficient for future clinical applications. We. therefore. plan to replace the colloidal gold tracer in the test kit with a more sensitive label such as an enzyme and also to determine the relationship between the $\mathrm{E} 7$ concentration and the progress of cervical cancer.

Acknow ledgments. This work was supported by the Korea Research Foundation Grant finded by the Korean Government (MOEHRD) (KRF-2005-041-D00261).

\section{References}

1. Walboomers, T. M; Jacobs, M. V.; Manos, M. M.; Bosch, F. X; Kummer, J. A.: Shah, K. V. J. Pathol 1999, 189, 12.

2. Gissmann, L.: Schneider, A. Tiral Etiologn' of Cenvical Cancer: Peto, R.: Hallsen, H. Z., Eds, Cold Spring Harbor: New York, NY, 1986; p. 217.

3. Nelson, P. H.; Vousden, K. H.; Hubbert, N. L.; Lowy, D. R.; Schiller, J. T. El $/ B O$. J. 1989, 8, 3905.

4. Dyson, N.: Howley, P. M.: Munger, K.: Harlow, E. Science 1989. 243,934 .

5. Scheffner, M. Cell $1993,75,495$.

6. DeFilippis, R. A.: Goodwin, E. C.; Wu, L.: DiMaio, D. J. Finol. 2003, 77, 155$]$

7. Huh, K. W.; DeMasi, I.; Ogawa, H.; Nakatani, Y.; Howley, P. M.; Munger, K. Proc. Natl .Acad. Sci. LS.4 2005, 102, 11492.

8. Jeon, S ; Lambert P. F. Proc. Natl. Acad. Sci. LSA 1995, 92, 1654.

9. Wilbur, D. C.: Cibas, E. S.; Merritt, S.; Tames, L. P.; Berger, B. M: Bonfiglio, T. A. Am. J. Chin. Pathol 1994, 101, 209.

10. Wertlake, P. J. Reprod. Hed 1999, t4, 11

11. Vince, A.; Kutela, N.; Iscic-Bes, T.; Hani, V.; Ivanisevic, M.; Sonicki, Z. J. Clin. Firol. 2002, 25, 109.

12. Pack, S. H.; Lee, S. H.: Cho, J. H.: Kim, Y. S. Methods 2000, $22,53$.

13. May, K. Ant. J. Obstet Gynecol 1991, 165, 2000

14. Ono, T.; Kawamura, M.; Arao, S.; Nariuchi, H. J. Immonol. Methods 2003, 272, 211

15. Chang, T. Y. Em. J. Biochem. 1985, 151,217.

16. Jeon, T. H.; Shin, D. M.; Cho, S. Y.; Song, K. Y.; Park, N. H.; Kang, H. S.; Kim, Y. D.; Kim, I. G. E.tp. Mol. Hed. 2007, 39, 621.

17. Cho, I. H.; Paek, E. H.; Kim, Y. K.; Kim, J. H.; Paek, S. H. Anal. Chim .tcta 2009, 632,247.

18. Mirecka, E. A.: Rudolph, R.: Hey, T. Protem Expr. Puif. 2006, 48 , 281 .

19. Chen, X. S.; Casini, G.; Harrison, S. C.; Garcea, R. L. J. Mol. Biol. $2001,307,173$

20. Jeon, J. H.; Cho, S. Y.: Kim, C. W.: Shin, D. M.: Kwon, J. C.: Choi, K. H. Exp. Hol. Hed. $2002,34,496$.

21. Ressler, S.; Scheiden, R; Dreier, K: Zwerschke, W. Clin. Cancen. Res. 2007, 12, 7067.

22. Cho, J. H.: Han, S. M.: Paek, E. H.; Cho, I. H.: Paek, S. H. Anal. Chem, 2006, 78, 793 .

23. Liang, Y. T; Chang, H. S.; Wang, C. Y.; Yu, W. C. Y. Int. J. Biochent Cell. Biol. 2008, 40, 2431 .

24. Nishimura, A.: Nakahara, T.; Ueno, T. A.; Sasaki, K.: Yoshida, S.; Kyo, S.: Howley, P. M.: Sakai, H. Microbes Infect. 2006, 8, 984.

25. Selvey, L. A.; Dum, L. A.; Murray, B.; Tindle, R. W; Frazer, I. H. J. Iirol. Wethod. 1992, 37, 119. 